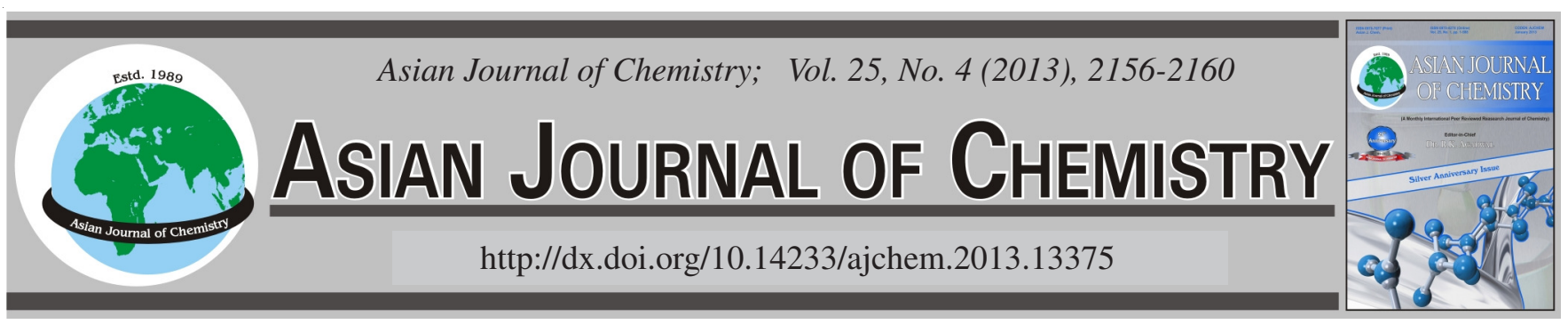

\title{
DFT Study on Effect of Hydrogen-Bond Formation on the Adsorption of Ethanol on Pd(111) Surface
}

\author{
Bin Huang ${ }^{*}$, Rong Chen and Quan Shui Chen*
}

Department of Materials Science and Engineering East China Institute of Technology, FuZhou 344000, P.R. China

*Corresponding author: Tel/Fax: +86 794 8258320; E-mail: bhuang@ecit.edu.cn; qshchen@ecit.cn

\begin{abstract}
DFT calculations have been performed to explore the ethanol adsorption on Pd (111) surfaces. Relative energies, equilibrium geometries, vibrational frequencies and electronic structures of monomer, dimer and one-dimensional (1D) chain of ethanol molecules adsorbed at the surface were investigated and analyzed. The calculations indicate that ethanol molecules prefer to adsorb at a top sites of the Pd (111) surface and the adsorption is exothermic. Adsorbed ethanol molecules are likely to form dimer and chain through the hydrogen bond interactions. The results also show that there are red shifts of $v(\mathrm{O}-\mathrm{H})$ frequencies for ethanol molecules adsorbed over the Pd (111) surface.
\end{abstract}

Key Words: DFT calculation, Ethanol, Pd (111) surface, dimer adsorption, 1D adsorption.

\section{INTRODUCTION}

Single-crystal processes studied at the atomic level from theoretical and experimental point of view are of special importance in surface science. Reactions of ethanol on transition metal surfaces is an important reaction for technological, economic and environmental reasons. Efficient catalysts for ethanol steam reforming have therefore attracted great attention and in particular noble metal-based catalysts have recently been developed for these reactions ${ }^{1-3}$. The previous study is directly relevant to ethanol decomposition on different metal surface and a number of experimental studies of these systems have been performed ${ }^{4-10}$. For example, on Pd (110) surface, molecular beam experiments show two competing pathways for ethanol dissociation after adsorption on the clean surface, the ethanol molecule decomposes via a surface ethoxy species either forming a methyl group, carbon monoxide and hydrogen, or by C-O bond scission ${ }^{11}$. In DFT calculations for ethanol on Pt (111) combined with transition state theory, the results show that the $\mathrm{C}-\mathrm{C}$ bond cleaves at a higher rate than the $\mathrm{C}-\mathrm{O}$ bond ${ }^{12}$.

In the past, in order to design molecules in crystals with particular structures and properties, many experiments focus on the molecule that engages in multiple specific interactions with neighbors, like alcohol and water molecules. Ethanol and water molecules in solvent have been studied and well documented in literatures ${ }^{13-15}$. One of distinct features found in these molecules is the existence of H-bond via hydroxyl groups between alcohol molecules and its significant effect on the reactivity and vibrations etc. However, the formation of hydrogen bond between ethanol molecules may compete with the bonding between ethanol molecules and metal surfaces and the interplay of these two types of interactions and their dependence on the substrates are critical for the adsorption pattern change.

In this paper, we present a systematic periodic density functional theory study for simulating the adsorption of mono ethanol, their dimers and 1D chain on Pd (111) surface. All adsorption systems have been studied in terms of structure, energetics and vibrational frequencies, which provide valuable insight into the interaction between adsorbate and substrate. The effect of forming H-bond of dimer and 1D chain on the geometries and electronic properties has also been explored by the difference of electron density.

\section{COMPUTATIONAL METHOD}

The DFT calculations was performed by double numerical basis sets with polarization function (the DNP basis set) implemented on the DMol3 package. Spin-unrestricted DFT in the generalized-gradient approximation (GGA) with the PerdewBurke-Ernzerhof (PBE) functional ${ }^{16,17}$ was used to obtain all the results given below. In the generation of numerical basis sets, the global orbital cutoff is chosen to be $4.1 \AA$. The energy tolerance in the self-consistent field calculations is set to $10^{-6}$ Ha. Optimized geometries were obtained using an energy convergence tolerance of $10^{-5} \mathrm{Ha}$ and a gradient convergence of $2 \times$ $10^{-3} \mathrm{Ha} / \AA$. 
We chose a three-layer slab to model Pd (111) surface with a vacuum of $15.00 \AA$ along the $\mathrm{z}$ direction. Supercells with periodicity $(3 \times 3),(4 \times 2),(3 \times 2)$ and $(2 \times 2)$ were used to simulate adsorption of the ethanol monomer, dimer and onedimensional (1D) chain structures at different coverage. The brillouin zone was sampled using the Monkhorst-Pack special k-point scheme with a $3 \times 3 \times 1$ mesh for structural optimization and total energy calculations. During the optimization steps, only the top layer of the three substrate layers are allowed to relax, together with the adsorbate layer.

The averaged adsorption energy with $\mathrm{N}$ ethanol molecules in the supercell, is defined as

$$
\mathrm{E}_{\text {ads }}^{\mathrm{N}}=\frac{\left(\mathrm{E}_{\text {eth/M }}^{\mathrm{N}}-\mathrm{N} \times \mathrm{E}_{\text {eth }}-\mathrm{E}_{\mathrm{M}}\right)}{\mathrm{N}}
$$

where $E_{e t h / M}^{N}, E_{e t h}$ and $E_{M}$ are the total energies of the adsorbed-substrate system, the isolated ethanol molecules in gas phase and the total energy of the bare metal slab, respectively. Here, a negative means the adsorption is exothermic.

\section{RESULTS AND DISCUSSION}

Ethanol monomer adsorption: The computed results for free ethanol molecule are presented in Fig. 1, the geometric parameters obtained for free molecule are in good agreement with available experimental data of $0.97,1.43$ and $1.51 \AA$ and $107.8^{\mathrm{o} 18}$. For monomer adsorption on Pd (111) surface, the structures are optimized within $(3 \times 3),(4 \times 2),(3 \times 2)$ and $(2$ $\times 2$ ) supercells for coverage of $1 / 9,1 / 8,1 / 6$ and $1 / 4 \mathrm{~mL}$, respectively. In fact, we searched for the most stable configuration of ethanol adsorption on Pd (111) surface, highsymmetry adsorption sites, top (T) site, two-fold bridge (B) and four-fold hollow $(\mathrm{H})$ all are considered, respectively. From our calculations, ethanol preferentially bonds to the top site, through the oxygen atom, irrespective to coverage, adsorption at hollow site is unstable. Fig. 1 shows the schematic plot for ethanol monomer adsorption on Pd (111) surface, the preferred configuration appeared to involve an $\mathrm{O}-\mathrm{H}$ bond that is roughly parallel and $\mathrm{C}-\mathrm{O}$ axis tilted to the surface as seen in Fig. 1. Table-1 displays their corresponding energetics, vibrational frequencies and geometries at different coverage $\theta(\mathrm{mL})$. We found that the interaction between ethanol and Pd surfaces is weak and the averaged adsorption energy is $-0.61 \mathrm{eV}$ at $1 / 9$ $\mathrm{mL}$. With an increase of ethanol coverage from $1 / 9$ to $1 / 4 \mathrm{~mL}$, the averaged adsorption energy decreases slightly $(0.1 \mathrm{eV})$ due to the steric repulsion. Correspondingly, the O-Pd bond length increases from 2.35-2.46 $\AA$. Compared to ethanol molecules in the gas phase, $\mathrm{C}-\mathrm{O}$ and $\mathrm{O}-\mathrm{H}$ bonds of adsorbed ethanol changes only slightly, irrespective of the coverage.

The vibrations of the isolated gas-phase ethanol molecule are calculated, the stretch frequency of the $\mathrm{OH}$ bond $v(\mathrm{OH}-)$, methyl bond $v\left(\mathrm{CH}_{3^{-}}\right)$and the C-C-O bend $v(\mathrm{C}-\mathrm{C}-\mathrm{O})$ are 3863 , 3088 and $1180 \mathrm{~cm}^{-1}$, respectively. Compared to the experimental values of 3660, 2965 and $1060 \mathrm{~cm}^{-1}$, our results are consistently $100-200 \mathrm{~cm}^{-1}$ higher, which is a typical error bar in DFT calculations ${ }^{19}$. For ethanol adsorption, the calculated $v\left(\mathrm{CH}_{3^{-}}\right)$and $v(\mathrm{C}-\mathrm{C}-\mathrm{O})$ vibrations at $1 / 9 \mathrm{~mL}$ are 3073 and 1220 $\mathrm{cm}^{-1}$, which is essentially unchanged from ethanol in gas. Accordingly, only the stretching frequencies $v(\mathrm{O}-\mathrm{H})$, which
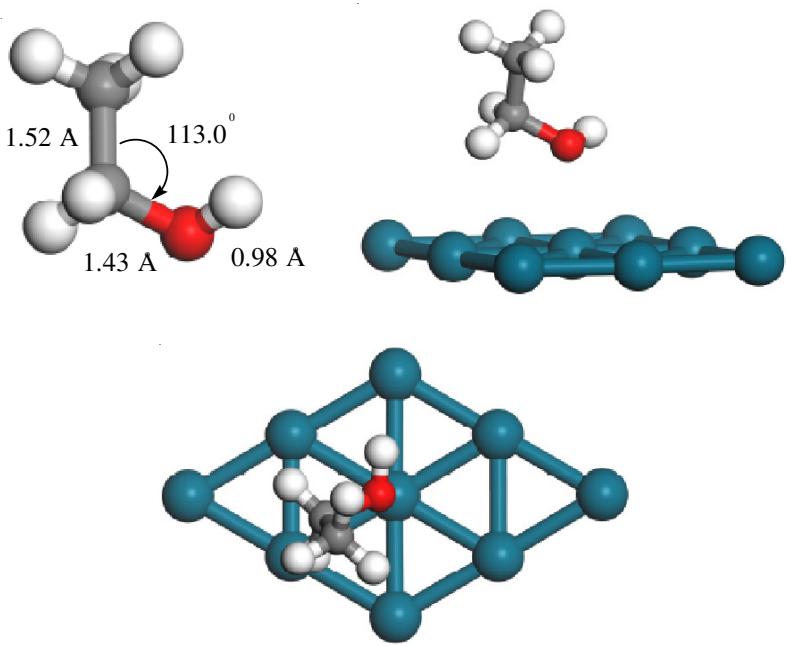

Fig. 1. Schematic plot for ethanol monomer adsorption on Pd (111) surface [side view (left) and top view (right)]. Red for oxygen, lighter gray for carbon and white for hydrogen

TABLE-1

AVERAGED ADSORPTION ENERGIES (eV) $\mathrm{E}_{\text {ads }}$ FOR MONOMER ADSORPTION AND CORRESPONDING MAIN STRUCTURAL PARAMETERS (A AND DEGREE), VIBRATIONAL FREQUENCIES $\left(\mathrm{cm}^{-1}\right)$ AT DIFFERENT COVERAGE $\theta(\mathrm{mL})$

\begin{tabular}{cccccc}
$\theta$ & $\mathrm{E}_{\text {ads }}$ & $\mathrm{O}-\mathrm{Pd}$ & $\mathrm{O}-\mathrm{H}$ & $\mathrm{C}-\mathrm{O}$ & $\mathrm{v}(\mathrm{O}-\mathrm{H})$ \\
\hline $1 / 9$ & -0.61 & 2.35 & 0.984 & 1.460 & 3589 \\
$1 / 8$ & -0.59 & 2.36 & 0.983 & 1.456 & 3573 \\
$1 / 6$ & -0.56 & 2.39 & 0.982 & 1.455 & 3514 \\
$1 / 4$ & -0.51 & 2.46 & 0.987 & 1.461 & 3480 \\
\hline
\end{tabular}

bonds directly to the surface, are listed in Table-1 and discussed in the following segments. Compared to the $\mathrm{v}(\mathrm{O}-\mathrm{H})$ of the free ethanol, vibration is softened noticeably by roughly 282 $\mathrm{cm}^{-1}$ upon adsorption for a coverage of $1 / 9 \mathrm{~mL}$, due to the coupling between adsorbed ethanol molecules and the substrate. The softness (red shift) increases with the coverage and our calculations show the largest red shift by $391 \mathrm{~cm}^{-1}$ observed at the coverage of $1 / 4 \mathrm{~mL}$.

Ethanol dimer adsorption: Two ethanol molecules were known as self-associate by forming hydrogen-bonded motifs in the previous work. In gas phase, our calculations show that the $\mathrm{H}$-bond formation is energetically favorable and $\mathrm{H}$-bond energy is predicted to be $-0.130 \mathrm{eV}$ per ethanol molecule. Optimized structures of ethanol dimers in gas phase are displayed in Fig. 2. Within the ethanol dimer, one molecule acts as the $\mathrm{H}$-donor, with the hydrogen of $\mathrm{OH}$ group participating in the H-bond toward the oxygen atom in the remained ethanol molecule, which serves as a $\mathrm{H}$-acceptor. In comparison with the isolated ethanol, main structural parameters of ethanol are intact and the $(\mathrm{O}(\mathrm{H}) \cdots \mathrm{H})$ hydrogen bond distances in gas phase is $2.855 \AA$.

The ethanol dimer are also found to be energetic on the $\mathrm{Pd}(111)$ surface within $(4 \times 2)$ and $(3 \times 2)$ supercells. However, due to the steric repulsion between the alkyls of two ethanol molecules, the dimer configuration is failed to form on $(2 \times 2)$ surface. Like ethanol monomer adsorption, two ethanol molecules tend to maintain the top site preference and two geometries with similar energetics are found in our calculations. The optimized structures of the ethanol dimer adsorption 

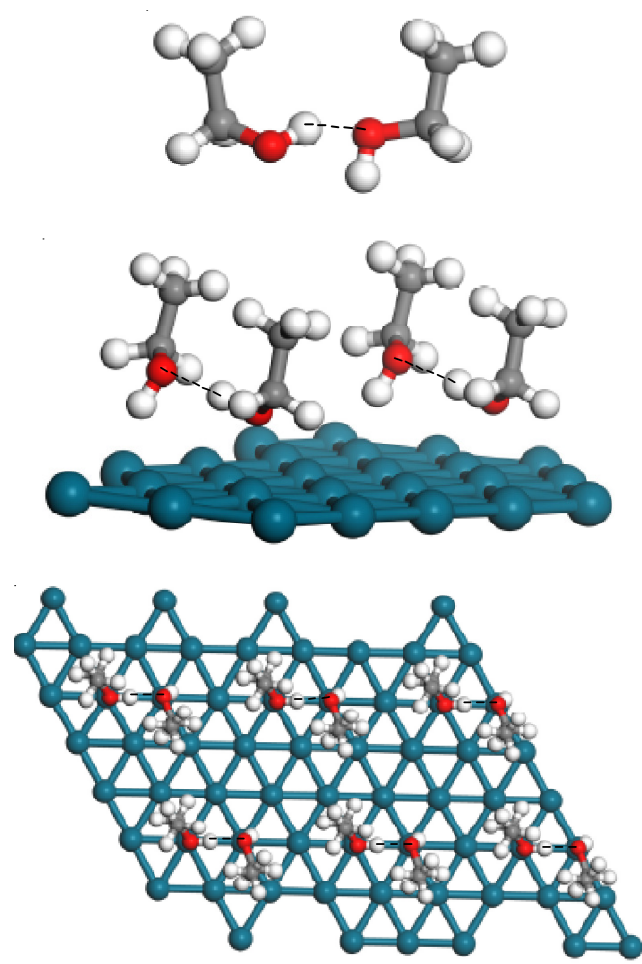

Fig. 2. Optimized structures of ethanol dimer in the gas phase (upper panel) and adsorption on $\operatorname{Pd}(111)$ surface (lower panel). Side view (left) and top view (right) have been shown

on Pd (111) surface are depicted in Fig. 2 and corresponding main structural parameters are tabulated in Table-2. As shown in Fig. 2, once adsorbed on the Pd (111) surface, two ethanol molecules remains tightly hydrogen bonded. Compared to the adsorption of monomer ethanol, for the one ethanol molecule as acceptor within dimer adsorption, the $\mathrm{O}-\mathrm{H}$ bonds tilted away from the normal direction of the surface, while for the other one as donor, $\mathrm{O}-\mathrm{H}$ bond almost parallels to the surface. The calculated distances are 2.263 and $3.217 \AA$ at the coverage of $1 / 4 \mathrm{~mL}$, respectively, from the oxygen atom of ethanol to $\mathrm{Pd}$ atom underneath. For adsorbed ethanol dimer at the coverage of $1 / 4 \mathrm{~mL}$, the $(\mathrm{O}(\mathrm{H}) \cdots \mathrm{H})$ distance along the $\mathrm{H}$ bond is 2.714 $\AA$, smaller by $0.141 \AA$ with respect to the dimer in gas phase because both two ethanol in the adsorbed dimer maintain the top site adsorption of metal surface.

As an approximation, the $\mathrm{H}$-bond energy, $\mathrm{E}_{\mathrm{H} \text {-bond }}$ (per ethanol molecule), is calculated by

$$
\mathrm{E}_{\mathrm{H}-\text { bond }}=\frac{\left(\mathrm{E}_{\text {dimer }}-2 \times \mathrm{E}_{\text {eth }}\right)}{2}
$$

where $\mathrm{E}_{\text {dimer }}$ is the total energy of frozen ethanol dimer taken from the optimized ethanol/substrate system in the absence of substrate and $\mathrm{E}_{\text {eth }}$ is the total energy of isolated ethanol molecule in gas phase. On the basis of the analytic expression eqn. 2, the calculated $\mathrm{H}$-bond energies for adsorption systems are $-0.112 \mathrm{eV}$ at the coverage of $1 / 4 \mathrm{~mL}$ and $-0.086 \mathrm{eV}$ at the coverage of $1 / 3 \mathrm{~mL}$, respectively. The averaged adsorption energy (per ethanol) are also given in Table-2 and they are $-0.77 \mathrm{eV}$ for $1 / 4 \mathrm{~mL}$ and $-0.75 \mathrm{eV}$ for $1 / 3 \mathrm{~mL}$, respectively. Contrast to previous study ${ }^{20,21}$, we also roughly divide adsorption energy into two parts, one is the bonding between the dimer and substrate and the other is H-bonding between the ethanol molecules in dimer. In our calculation, the predicted $\mathrm{H}$-bond energy accounting for $15 \%$ of the overall energy gain, show that the adsorbate-substrate bonding is dominant for the dimer adsorption in this case.

Although the energy contribution is modest, H-bond has significant effect on $\mathrm{OH}$ vibration. For the gas-phase ethanol dimer, the calculated $\mathrm{v}(\mathrm{OH})$ are $3482 \mathrm{~cm}^{-1}$ for the H-donor ethanol and $3629 \mathrm{~cm}^{-1}$ for the $\mathrm{H}$-acceptor ethanol, in contrast to $3871 \mathrm{~cm}^{-1}$ for the free monomer. After adsorption, the $\mathrm{v}(\mathrm{OH})$ stretches become $3094 \mathrm{~cm}^{-1}$ (for the H-donor) and $3448 \mathrm{~cm}^{-1}$ (for the $\mathrm{H}$-acceptor) at $1 / 4 \mathrm{~mL}$ and $2974 \mathrm{~cm}^{-1}$ (for the $\mathrm{H}$ donor) and $3243 \mathrm{~cm}^{-1}$ (for the $\mathrm{H}$-acceptor) at $1 / 3 \mathrm{~mL}$. These vibrational calculations show that adsorption results in additional red shift. Furthermore, the red shift for the Hacceptor indicates there is coupling even between the higherlying ethanol molecule and metal substrate. In comparison of the ethanol dimer in gas phase, both of the $\mathrm{O}-\mathrm{H}$ bonds are elongated by $0.02 \AA$.

Ethanol 1D chain adsorption: The adsorbed ethanol dimers can agglomerate further to form one-dimensional (1D) zigzag chain through the $\mathrm{H}$-bond on $\mathrm{Pd}$ (111) at coverage of $1 / 4$ and 1/3 mL (Fig. 3). As shown in Fig. 3 and Table-3, two ethanol molecules adsorbs in $\mathrm{Pd}$ super cell on top position, the $\mathrm{C}-\mathrm{C}$ bond in one ethanol molecule tilted away from the normal direction of the surface, while for the other one, C-C bond almost parallels to the surface, the calculated the O-Pd bond length are 2.298 and $3.046 \AA$ at $1 / 4 \mathrm{~mL}, 2.321$ and 3.210 $\AA$ at $1 / 3 \mathrm{~mL}$, respectively. Within 1D ethanol adsorption, a distinct feature is that all of the hydroxyl groups participate in the H-bond. The lower-lying molecule binds directly to the surface through the $\mathrm{O}$ atom, while the higher-lying one forms the H-bond to the lower-lying ethanol molecule in the next unit cell. Each hydroxyl group acts simultaneously as the $\mathrm{H}$-donor and $\mathrm{H}$-acceptor in the zigzag chain. The ratio between the number of the H-bonds to ethanol molecules is $1: 1$, compared to $1: 2$ for the adsorbed ethanol dimer, where only one H-bond forms between two adsorbed ethanol molecules.

TABLE-2

AVERAGED ADSORPTION ENERGIES (eV) $\mathrm{E}_{\text {ads }}$ FOR DIMER ADSORPTION AND CORRESPONDING MAIN STRUCTURAL PARAMETERS ( $\AA$ AND DEGREE), VIBRATIONAL FREQUENCIES $\left(\mathrm{cm}^{-1}\right)$, AT DIFFERENT COVERAGE $\theta(\mathrm{mL})$

\begin{tabular}{cccccccc}
\hline$\theta$ & $\mathrm{E}_{\text {ads }}$ & $\mathrm{E}_{\mathrm{H}-\mathrm{bond}}$ & $\mathrm{O}-\mathrm{Pd}$ & $\mathrm{O}-\mathrm{H}$ & $\mathrm{O}_{\mathrm{a}}-\mathrm{O}_{\mathrm{b}}$ & $\mathrm{C}-\mathrm{O}$ & $\mathrm{v}(\mathrm{O}-\mathrm{H})$ \\
\hline Gas phase & - & -0.130 & - & 0.980 & 2.855 & 1.429 & 3482 \\
- & - & - & - & 0.987 & - & 1.442 & 3629 \\
$1 / 4$ & -0.77 & -0.112 & 2.263 & 1.01 & 2.714 & 1.452 & 2974 \\
- & & & 3.217 & 1.00 & - & 1.453 & 3243 \\
$1 / 3$ & -0.75 & -0.086 & 2.313 & 1.01 & 2.726 & 1.451 & 3055 \\
- & - & - & 3.323 & 0.99 & - & 1.451 & 3270 \\
\hline
\end{tabular}



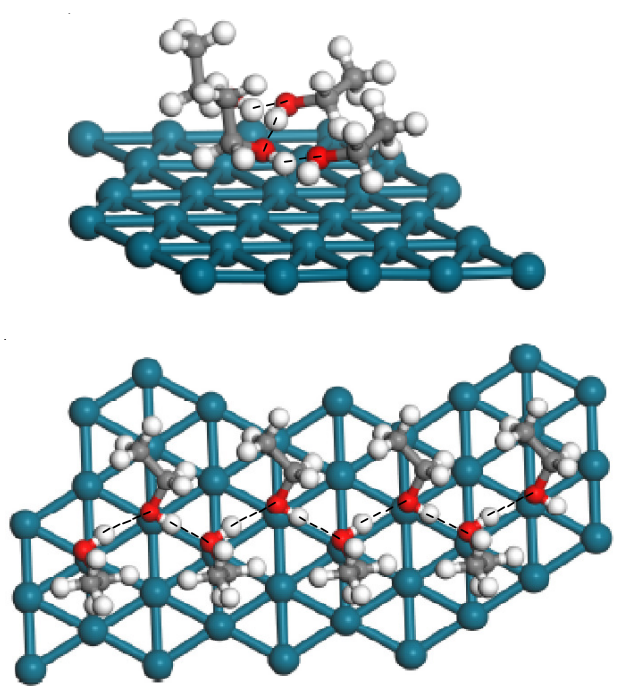

Fig. 3. Top view (left) and side view (right) of $1 \mathrm{D}$ ethanol chain on the $\operatorname{Pd}(111)$ surface

\begin{tabular}{|c|c|c|c|c|c|c|}
\hline \multicolumn{7}{|c|}{$\begin{array}{c}\text { TABLE-3 } \\
\text { AVERAGED ADSORPTION ENERGIES (eV) E } \text { ads }_{\text {ads }} \text { FOR } \\
\text { ONE-DIMENSIONAL CHAIN ADSORPTION AND } \\
\text { CORRESPONDING MAIN STRUCTURAL PARAMETERS } \\
(\AA \text { AND DEGREE), VIBRATIONAL FREQUENCIES } \\
\left(\mathrm{cm}^{-1}\right) \text { AT DIFFERENT COVERAGE } \theta(\mathrm{mL})\end{array}$} \\
\hline$\theta$ & $\mathrm{E}_{\mathrm{ads}}$ & $\mathrm{E}_{\text {H-bond }}$ & O-Pd & O-H & $\mathrm{C}-\mathrm{O}$ & $v(\mathrm{O}-\mathrm{H})$ \\
\hline $1 / 4$ & -0.78 & -0.190 & 2.298 & 1.001 & 1.450 & 3008 \\
\hline - & - & - & 3.046 & 0.995 & 1.451 & 3226 \\
\hline $1 / 3$ & -0.76 & -0.216 & 2.321 & 1.003 & 1.450 & 3027 \\
\hline - & - & - & 3.210 & 0.995 & 1.453 & 3318 \\
\hline
\end{tabular}

The gained total energy upon forming the $1 \mathrm{D}$ chain are $-0.78 \mathrm{eV}$ at $1 / 4 \mathrm{~mL}$ and $-0.76 \mathrm{eV}$ at $1 / 3 \mathrm{~mL}$, respectively, which is almost unchanged contrast to the dimer adsorption on $\operatorname{Pd}(111)$ surface, but the ratio between the adsorbate-substrate bonding and $\mathrm{H}$-bonding to overall energetics has been significantly changed. Using eqn. 2, we obtained the H-bond energy per ethanol molecule of $-0.190 \mathrm{eV}(1 / 4 \mathrm{~mL})$ and $-0.216 \mathrm{eV}$ $(1 / 3 \mathrm{~mL})$, respectively, the $\mathrm{H}$-bonding account for roughly $34 \%$ of the overall energies at $1 / 3 \mathrm{~mL}$, contrast to $15 \%$ for the dimer adsorption at same coverage. The dominant role of the H-bonding in the overall energetics for 1D ethanol chain comes from increased numbers of the $\mathrm{H}$-bond.

The O-H vibrations have been affected by formation of the $1 \mathrm{D}$ ethanol chain. The calculated $v(\mathrm{OH})$ is $3008 \mathrm{~cm}^{-1}$ for the lower-lying molecule and $3226 \mathrm{~cm}^{-1}$ for the higher-lying one at coverage of $1 / 4 \mathrm{~mL}$. With increase of the coverage to $1 / 3 \mathrm{~mL}$, corresponding vibrations become 3027 and $3318 \mathrm{~cm}^{-1}$. Compared to the dimer adsorption, the $v(\mathrm{OH})$ of the higherlying ethanol molecules has been softened further, due to its direct participation into the hydrogen bond, the $\mathrm{v}(\mathrm{OH})$ for the lower-lying ethanol are less affected because the transition from the dimer to $1 \mathrm{D}$ chain mainly change the bonding of the higher-lying ethanol molecules. Our results also show that these two kinds of interaction result in the overall red shift of $v(\mathrm{OH})$ to the magnitude of $851 \mathrm{~cm}^{-1}$, which is accidentally overlapped with the $v\left(\mathrm{CH}_{3}\right)$, so we must caution the existence of the distinct pair of $\mathrm{OH}$ vibrations which can be used as the fingerprint for alcohol adsorption modes and the formation of the H-bond.
Analysis of electronic structure: Fig. 4 presents profiles of the averaged adsorption energies and H-bond energies per ethanol molecule for ethanol monomer, dimer and 1D chain at different coverages. As shown in Fig. 4, it can be found that the overall energy obtained from the ethanol adsorption on Pd (111) is exothermic and the averaged adsorption energy decreases with coverage. Ethanol molecules are energetically favorable to form the dimer via the H-bond formation, the lateral interaction between adsorbed dimers is modest, as seen from little change of the averaged adsorption energy at the coverage of $1 / 4$ and $1 / 3 \mathrm{~mL}$. The present calculations also confirm that the adsorbed ethanol dimers may rearrange themselves to form 1D chain by forming additional hydrogen bond between adsorbed dimers. Though its overall energetics are very close to the adsorbed dimer, the H-bonding becomes dominant and accounts for $c a .31 \%$ of the overall energy gain with weakened adsorbate-substrate interaction.

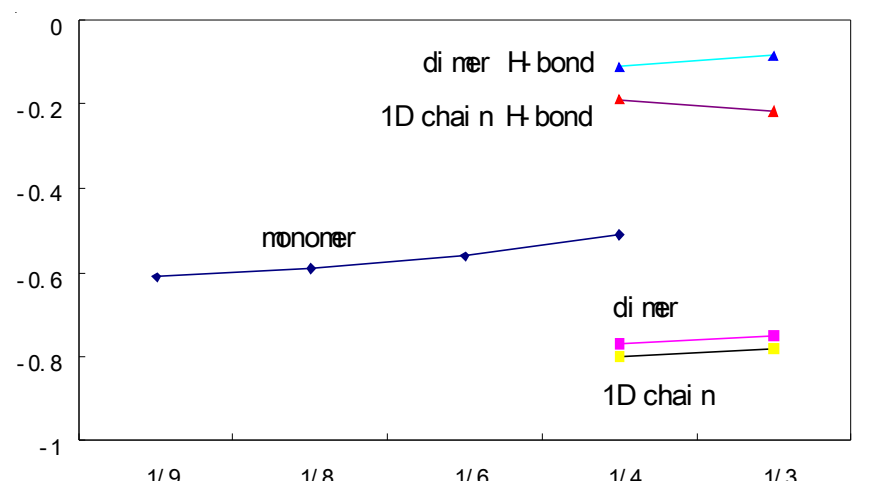

Fig. 4. Profiles of the averaged adsorption energies and H-bond energies per ethanol molecule for ethanol monomer, dimer and 1D chain at different coverages

To further elucidate the nature of interaction between ethanol molecules and Pd (111) surface, the difference of electron density of adsorbate-substrate system is plotted in Fig. 5 using the formula given below:
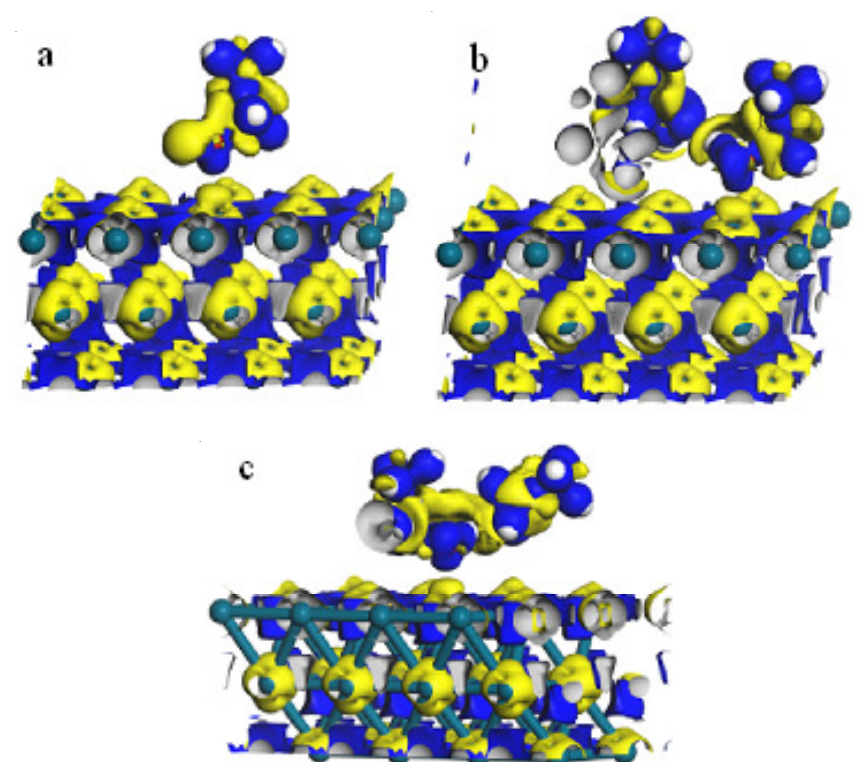

Fig. 5. Isosurfaces of the difference of electron density (a) ethanol monomer adsorption (b) ethanol dimer adsorption (c) 1D ethanol chain adsorption. Yellow contours indicate electron depletion and blue contours indicate electron accumulation 


$$
\Delta \rho=\rho(\mathrm{Pd}+\Sigma \text { ethanol })-\Sigma \rho(\text { ethanol })-\rho(\mathrm{Pd})
$$

where $\rho\left(\operatorname{Pd}+\sum\right.$ ethanol $)$ is the electron density of adsorbatesubstrate system and $\rho(\mathrm{Pd})$ and $\rho$ (ethanol) describe the electron density of the substrate and isolated adsorbates abstracted from the combined system, respectively. As shown in Fig. 5a, it can be found that the adsorption induces pronounced electron transfer from the $\mathrm{H}$ atom of the $\mathrm{OH}$ group to oxygen and polarization of $\mathrm{Pd}$ atom underneath. The difference of electron density images for ethanol dimer adsorption is plotted in Fig. $5 \mathrm{~b}$, the electron along the $\mathrm{H}$-bond has been polarized with the directional H-bond formation and this polarization has been enhanced for 1D ethanol chain with increase of the H-bond, as shown in Fig. 5c. Presumably, adsorption may induce electronic perturbation toward the substrate decrease and coupling between the adsorbates and substrate has been relatively weakened, which is in an agreement with the energetics found in above. Using the Mulliken partitioning of the electron density, we also have performed a population analysis when ethanol are adsorbed on the $\operatorname{Pd}(111)$ surface. The calculated mulliken are -0.629 on $\mathrm{O}$ atom and 0.038 on $\mathrm{Pd}$ atom underneath for monomer adsorption and -0.597 on $\mathrm{O}$ atom and 0.053 on $\mathrm{Pd}$ atom underneath of lower-lying ethanol molecule for dimer adsorption, respectively, this results indicate hydrogen-bond formation leads to remarkable structural and electronic effects for ethanol dimer adsorption on $\operatorname{Pd}(111)$ surface.

\section{Conclusion}

In the present study, the adsorption of ethanol on Pd (111) surface was studied systematically by density functional theory. For all adsorption systems, ethanol molecule adsorption is exothermic by binding to top site on the Pd (111) surface. The present calculations indicate that the adsorbed ethanol dimers may rearrange themselves to form $1 \mathrm{D}$ chain by forming additional hydrogen bond between adsorbed dimers. Though its overall energetics are very close to the adsorbed dimer, the $\mathrm{H}$-bonding becomes dominant and accounts for about $31 \%$ of the overall energy gain with weakened adsorbate-substrate interaction. Our results also show that these two kinds of interaction result in the overall red shift of $v(\mathrm{OH})$ to the magnitude of $769 \mathrm{~cm}^{-1}$, which is accidentally overlapped with the $v\left(\mathrm{CH}_{3}\right)$ of ethanol, we must caution the existence of the distinct pair of $\mathrm{OH}$ vibrations which can be used as the fingerprint for alcohol adsorption modes and the formation of the H-bond, accordingly.

\section{ACKNOWLEDGEMENTS}

This work was supported by the Foundation of Jiangxi Educational Committee (No. GJJ11487).

\section{REFERENCES}

1. R.D. Cortright, R.R. Davda and J.A. Dumesic, Nature, 418, 964(2002).

2. F.G. Aalves, P.R.S. Medeiros, J.G. Eon and L. Appel, Appl. Catal. A, 193, 195 (2000).

3. W. Wang, Z. Wang, Y. Ding, J. Xi and G. Ly, Catal. Lett., 81, 63 (2002).

4. J.Z. Xu, X.P. Zhang and R. Zenobi, J. Surf. Sci., 256, 288 (1991).

5. T. Kartochwil, Wittmann and J. Kuppers, J. Electron Spectrosc. Relat. Phenom., 609, 65 (1993).

6. Z.J. Tian, X.M. Wei, R.S. Zhai, S.Z. Ren, D.B. Liang and L.W. Lin, Chem. J. Chin. Univ., 7, 1153 (1997).

7. M. Mavrikakis and M. Barteau, J. Mol. Catal. A, 131, 135 (1998).

8. C.J. Houtman and M.A. Barteau, J. Catal., 130, 528 (1991).

9. E. Vesselli, A. Baraldi, G. Comelli, S. Lizzit and R. Rosei, ChemPhysChem., 5, 1133 (2004).

10. Y. Qian, C.Y. Wang and Z.G. Le, Appl. Surf. Sci., 257, 10758 (2011).

11. M. Bowker, R.P. Holroyd, R.G. Scharpe, J.S. Corneille, S.M. Francis and D.W. Goodman, Surf. Sci., 370, 113 (1997).

12. K.I. Gursahani, R. Alcala, R.D. Cortright and J.A. Dumesic, Appl. Catal. A, 222, 369(2001).

13. P. Lalanne, J.M. Andanson and J.C. Soetens, J. Phys. Chem. A, 108, 3902 (2004).

14. U. Liddel and E .Becker, Spectrochim. Acta, 10, 70 (1957).

15. W. George, T. Has, M. Hossain, B. Jones and R.J. Lewis, Chem. Soc. Faraday Trans., 94, 2701 (1998).

16. J.P. Perdew, K. Burke and M. Ernzerhof, Phys. Rev. Lett., 77, 3865 (1996).

17. J.P. Perdew, K. Burke and M. Ernzerhof, Phys. Rev. Lett., 78, 1396 (1997).

18. R. Ludwig, F. Weinhold and T.C. Farrar, Mol. Phys., 97, 465 (1999).

19. S. Meng, L.F. Xu, E.G. Wang and S.W. Gao, Phys. Rev. Lett., 89, 176104 (2002).

20. B. Huang, Y. Qian and Q.S. Chen, Chin. J. Struct. Chem., 12, 1742 (2011).

21. M.M. Yang, X.H. Bao and W.X. Li, J. Phys. Chem. C, 111, 7403 (2007). 